\title{
Pemanfaatan Metode Forward Chaining Dalam Pengembangan Sistem Pakar Pendiagnosa Kerusakan Televisi Berwarna
}

\author{
Gusti Ayu Dessy Sugiharni \\ Sistem Informasi \\ STMIK STIKOM Bali \\ Denpasar, Indonesia \\ dessysugiharni@gmail.com
}

\author{
Dewa Gede Hendra Divayana \\ Pendidikan Teknik Informatika \\ Universitas Pendidikan Ganesha \\ Singaraja, Indonesia \\ hendra.divayana@undiksha.ac.id
}

\begin{abstract}
Sistem pakar pada penelitian ini merupakan sistem pakar berbasis desktop yang menghadirkan solusi dalam mendeteksi dan memberikan informasi detail tentang kerusakankerusakan pada TV berwarna. Sistem pakar ini menyediakan fasilitas konsultasi yang digunakan untuk memudahkan melakukan interaksi tanya-jawab antara sistem dengan pemakai. Sistem juga menyediakan fasilitas edit pengetahuan yang dapat digunakan oleh perekayasa pengetahuan dalam melakukan perubahan data pada basis pengetahuan. Metode penelusuran solusi yang digunakan pada sistem ini adalah adalah penelusuran runut maju (forward chainning). Aturan pada basis pengetahuan dimodelkan sebagai tabel keputusan dengan memanfaatkan database Access serta bahasa pemrograman Visual Basic 6.0. Pemanfaatan database untuk menyimpan basis pengetahuan dari sistem pakar akan mempermudah dalam pembuatan fasilitas penambahan pengetahuan. Dengan adanya fasilitas penambahan pengetahuan, perubahan aturan pada basis pengetahuan dan pengembangan sistem melalui akuisisi pengetahuan yang baru dapat langsung dilakukan tanpa harus membongkar sistem yang sudah jadi.
\end{abstract}

Keywords-Sistem Pakar, Kerusakan TV Berwarna, Forward Chaining

\section{PENDAHULUAN}

Perkembangan teknologi informasi sekarang ini berjalan sangan cepat dan memegang peranan penting dalam berbagai hal. Komputer merupakan salah satu bagian penting dalam peningkatan teknologi informasi. Kemampuan komputer dalam mengingat dan menyimpan informasi dapat dimanfaatkan tanpa harus bergantung kepada hambatanhambatan seperti yang dimiliki pada manusia, misalnya saja kondisi lapar, haus ataupun emosi. Dengan menyimpan informasi dan sehimpunan aturan penalaran yang memadai memungkinkan komputer memberikan kesimpulan atau mengambil keputusan yang kualitasnya sama dangan kemampuan seorang pakar bidang keilmuan tertentu. Salah satu cabang ilmu komputer yang dapat mendukung hal tersebut adalah sistem pakar.

Sistem pakar merupakan salah satu cabang kecerdasan buatan yang mempelajari bagaimana "mengadopsi" cara seorang pakar berpikir dan bernalar dalam menyelesaikan suatu permasalahnan, dan membuat suatu keputusan maupun mengambil kesimpulan dari sejumlah fakta yang ada. Dasar dari suatu sistem pakar adalah bagaimana mentansfer pengetahuan yang dimiliki oleh seorang pakar ke dalam komputer, dan bagaimana membuat keputusan atau engambil kesimpulan berdasarkan pengetahuan itu.

Sampai saat ini sudah ada beberapa hasil perkembangan sistem pakar dalam berbagai bidang sesuai dengan kepakaran seseorang misalnya bidang pendidikan, kedokteran maupun bidang yang menyangkut perbaikan peralatan elektronik khususnya televisi berwarna. Televisi berwarna merupakan salah satu peralatan elektronik yang sering mengalami gangguan atau kerusakan sehingga dengan mengandalkan kemajuan di bidang teknologi dan informasi tersebut, kiranya perlu adanya pembuatan sebuah "Sistem Pakar Pendiagnosa Kerusakan Pada Televisi Berwarna" dan memberikan bekal pengetahuan dan pembelajaran yang menyangkut kerusakan pada televisi berwarna dengan memanfaatkan komputer sebagai media pembelajaran.

Pemilihan masalah menyangkut kerusakan-kerusakan pada televisi berwarna dijadikan sebagai sistem pakar adalah kenyataan bahwa kerusakan-kerusakan pada sebuah televisi berwarna sering kali menggangu pengguna televisi, sehingga perlu adanya solusi untuk menangani hal-hal kerusakan pada 
televisi berwarna tersebut melalui teknologi komputer yang didalamnya terdapat software yang dapat membantu memecahkan masalah kerusakan-kerusakan yang terjadi.

Sistem pakar pada penelitian ini merupakan sistem pakar berbasis desktop yang menghadirkan solusi dalam mendeteksi dan memberikan informasi detail tentang kerusakan-kerusakan pada TV berwarna. Sistem pakar ini menyediakan fasilitas konsultasi yang digunakan untuk memudahkan melakukan interaksi tanya-jawab antara sistem dengan pemakai. Sistem juga menyediakan fasilitas edit pengetahuan yang dapat digunakan oleh perekayasa pengetahuan dalam melakukan perubahan data pada basis pengetahuan. Metode penelusuran solusi yang digunakan pada sistem ini adalah adalah penelusuran runut maju (forward chainning). Aturan pada basis pengetahuan dimodelkan sebagai tabel keputusan dengan memanfaatkan database Access serta bahasa pemrograman Visual Basic 6.0. Pemanfaatan database untuk menyimpan basis pengetahuan dari sistem pakar akan mempermudah dalam pembuatan fasilitas penambahan pengetahuan. Dengan adanya fasilitas penambahan pengetahuan, perubahan aturan pada basis pengetahuan dan pengembangan sistem melalui akuisisi pengetahuan yang baru dapat langsung dilakukan tanpa harus membongkar sistem yang sudah jadi.

\section{KAJIAN PUSTAKA}

\section{A. Sistem Pakar}

Sistem pakar (expert system) adalah salah satu bagian dari kecerdasan buatan yang menggabungkan dasar-dasar pengetahuan dan mesin inferensial agar dapat mengadopsi kemampuan ahli menjadi alat untuk memecahkan masalah seperti apa yang ahli lakukan [1].

Sistem pakar merupakan cabang dari Artificial Intelligence yang secara khusus menggunakan pengetahuan untuk memecahkan masalah di tingkat ahli [2]. Sistem Pakar adalah salah satu teknik penalaran terkenal yang digunakan dalam domain aplikasi diagnosis. Pada sistem pakar, pengetahuan manusia tentang keahlian tertentu untuk menyelesaikan tugas tertentu direpresentasikan sebagai fakta dan aturan dalam basis pengetahuan [3]. Sistem Expert adalah perangkat lunak yang mensimulasikan kinerja ahli dalam bidang tertentu. Sistem pakar saat ini telah digunakan di banyak daerah di mana memerlukan pengambilan keputusan atau memprediksi dengan keahlian[4]. Sistem pakar adalah sistem kecerdasan buatan yang menggabungkan basis pengetahuan dengan mesin inferensi sehingga dapat mengadopsi kemampuan ahli ke dalam komputer, sehingga komputer dapat memecahkan masalah seperti sering dilakukan oleh ahli-ahli [5].

Dari beberapa definisi tersebut, maka dapat diambil kesimpulan umum yaitu sistem pakar merupakan sistem yang mengadopsi kemampuan para pakar, sehingga sistem dapat memecahkan permasalahan pada domain tertentu seperti yang biasanya dilakukan oleh para pakar.

1. Bentuk Sistem Pakar

Ada empat bentuk sistem pakar, yaitu :

a. Berdiri sendiri.

Sistem pakar jenis ini merupakan software yang berdiri sendiri tidak tergabung dengan software yang lainnya.

b. Tergabung.

Sistem pakar jenis ini merupakan bagian program yang terkandung di dalam suatu algoritma atau merupakan program dimana di dalamnya memanggil algoritma sub rutin lain.

c. Menghubungkan ke software lain.

Bentuk ini biasanya merupakan sistem pakar yang menghubungkan ke suatu paket program tertentu, misalnya dengan $D B M S$.

d. Sistem mengabdi.

Sistem pakar ini merupakan bagian dari komputer khusus yang dihubungkan dengan suatu fungsi tertentu. Misalnya : sistem pakar yang digunakan untuk membantu menganalisis data radar.

\section{Ciri-ciri Sistem Pakar}

Sistem pakar yang baik harus memenuhi ciri-ciri sebagai berikut :

a. Memiliki fasilitas informasi yang handal.

b. Mudah dimodifikasi.

c. Dapat digunakan dalam berbagai jenis komputer.

3. Struktur Sistem Pakar

Struktur sistem pakar terdiri dari dua bagian pokok, yaitu lingkungan pengembangan (development environment) dan lingkungan konsultasi (consultation environment). Lingkungan pengembangan digunakan sebagai pembangun sistem pakar baik dari segi pembangun komponen maupun basis pengetahuan. Lingkungan konsultasi digunakan oleh seseorang yang bukan ahli untuk berkonsultasi.

\section{Komponen Sistem Pakar}

Sistem pakar memiliki beberapa komponen utama yang terdiri dari :

a. Basis Pengetahuan (Knowledge Base)

Basis pengetahuan berisi pengetahuan-pengetahuan dalam penyelesaian masalah. Ada dua bentuk pendekatan basis pengetahuan yang sangat umum digunakan, yaitu :

1) Penalaran berbasis aturan (Rule-Based Reasoning)

Pada penalaran berbasis aturan, pengetahuan direpresentasikan dengan menggunakan aturan 
berbentuk : IF - THEN. Bentuk ini digunakan apabila kita memiliki sejumlah pengetahuan pakar pada suatu permasalahan tertentu, dan si pakar dapat menyelesaikan masalah tersebut secara berurutan. Disamping itu, bentuk ini juga digunakan apabila dibutuhkan penjelasan tentang jejak (langkah-langkah) pencapaian solusi.

\section{2) Penalaran berbasis kasus (Case-Based Reasoning)}

Pada penalaran berbasis kasus, basis pengetahuan akan berisi solusi-solusi yang telah dicapai sebelumnya, kemudian akan diturunkan suatu solusi untuk keadaan yang terjadi sekarang (fakta yang ada). Bentuk ini digunakan apabila user menginginkan untuk tahu lebih banyak lagi pada kasus-kasus yang hampir sama (mirip). Selain itu, bentuk ini juga digunakan apabila kita telah memiliki sejumlah situasi atau kasus tertentu dalam basis pengetahuan.

b. Motor Inferensi (Inference Engine)

Motor inferensi (inference engine) berisi metodologi yang digunakan untuk melakukan penalaran terhadap informasi-informasi dalam basis pengetahuan serta digunakan untuk memformulasikan konklusi.

Motor inferensi merupakan bagian yang mengandung mekanisme fungsi berpikir dan pola-pola penalaran sistem yang digunakan oleh seorang pakar. Mekanisme akan menganalisa suatu masalah tertentu dan selanjutnya akan mencari jawaban, kesimpulan atau keputusan yang terbaik. Karena itu Inference Engine merupakan bagian terpenting dari sistem pakar yang berperan dalam menentukan efektifitas dan efisiensi sistem.

Ada dua cara yang dapat dikerjakan dalam melakukan inferensi, yaitu [6]:

\section{1) Forward Chaining (Alur Maju)}

Forward Chaining merupakan strategi yang digunakan dalam Sistem Pakar untuk mendapatkan kesimpulan/keputusan yang dimulai dengan menelusuri fakta-fakta dan tempat [7].

Forward Chaining adalah pencocokan fakta atau pernyataan dimulai dari bagian sebelah kiri (IF dulu). Dengan kata lain, penalaran dimulai dari fakta terlebih dahulu untuk menguji kebenaran hipotesis. Pada sistem alur maju, fakta-fakta dalam sistem disimpan dalam memori kerja dan secara kontinyu diperbaharui. Keluaran dalam sistem merepresentasikan aksi-aksi yang harus diambil apabila terdapat suatu kondisi khusus pada item- item dalam memori kerja atau sering disebut kondisi aksi. Kondisi biasanya berupa penambahan atau penghapusan item dalam memori kerja. Berikut contoh inferensi dengan menggunakan metode alur maju, yaitu :

JIKA demam tinggi dan bintik-bintik merah

MAKA penderita terkena penyakit demam berdarah

2) Backward Chaining (Alur Mundur)

Backward Chaining adalah pencocokan fakta atau pernyataan dimulai dari bagian sebelah kanan (THEN dulu). Dengan kata lain, penalaran dimulai dari hipotesis terlebih dahulu, dan untuk menguji kebenaran hipotesis tersebut harus dicari fakta-fakta yang ada dalam basis pengetahuan.

3) Antarmuka Pemakai

Antarmuka pemakai merupakan bagian penghubung antara program aplikasi sistem pakar dengan pemakai. Biasanya pada bagian ini akan terjadi dialog atau menu-menu pilihan yang nantinya harus dijawab oleh pemakai agar sistem pakar dapat mengambil keputusan berdasarkan jawaban dari pemakai tersebut.

\section{Arsitektur Sistem Pakar}

Arsitektur sistem pakar terdiri dari tiga bagian pokok atau utama yang digunakan sebagai acuan dalam menyelesaikan suatu masalah agar dapat memenuhi kriteria sistem pakar tersebut. Adapun tiga bagian pokok atau utama sistem pakar itu adalah:

a. Knowledge Acquisition Facility (fasilitas pengembangan basis pengetahuan).

Banyak sistem pakar mempunyai dedikasi modul untuk mengupdate proses. Modul atau set modul ini dinamakan dengan Knowledge Acquisition Facility (fasilitas pengembangan basis pengetahuan). Informasi pengetahuan terhadap sebagian besar sistem pakar akan diperbaharui dan akan bertambah banyak dalam sistem. Hal ini dilakukan untuk dapat membantu menyelesaikan masalah.

b. Explanation Facility (fasilitas penjelasan).

Salah satu fungsi sebagian besar sistem pakar akan berisi pembenaran (pertanyaan). Fungsi pembenaran mengijinkan kepada para user bertanya kepada sistem pakar untuk membenarkan jawaban atau memberitahu bahwa sistem sudah terisi.

Explanation facility menyimpan track untuk memberitahu dan memberi konsultasi-konsultasi dengan bagian alasan menggunakan inferensi engine (mesin kesimpulan) untuk memberitahu hasil. Dalam beberapa waktu selama sesi interaktif dengan sistem pakar, para pengguna dapat bertanya kepada sistem bagaimana sampai 
sistem tersebut dapat memberi kesimpulan, dan explanation facility akan merespon dengan cepat, dan akan memberikan jawaban dengan baik.

c. Self Training Facility (fasilitas belajar adaptif).

Para pakar belajar situasi, menyediakan pemberitahuan/informasi mengamati hasil dari hasil informasi dan menyimpan semua informasi ke dalam memori sistem. Pemberitahuan yang baru ini dikembangkan dan pengetahuan yang baru menentukan penambahan kepakaran para pakar. Pakar merubah kepakaran mereka di dalam self training facility.

Self training facility merupakan tujuan lain untuk sistem pakar. Ketika sistem pakar memperoleh fakta baru maka selanjutnya menyimpulkan semua prosedur. Faktafakta baru ini semua dapat dibuat pada knowledge base dan kemudian akan dipresentasikan kepada pengguna.

Self training facility menerima fakta-fakta pada sistem pakar dengan inference engine untuk menghasilkan dan membandingkan fakta-fakta yang berasal dari domain database, maka secara langsung dibuat basis data yang baru.

Self training facility juga akan mencoba untuk mengetahui jika fakta spesifik untuk masalah secara umum dalam general sistem pakar. Untuk lebih jelasnya, arsitektur sistem pakar dapat dilihat pada Gambar 1.

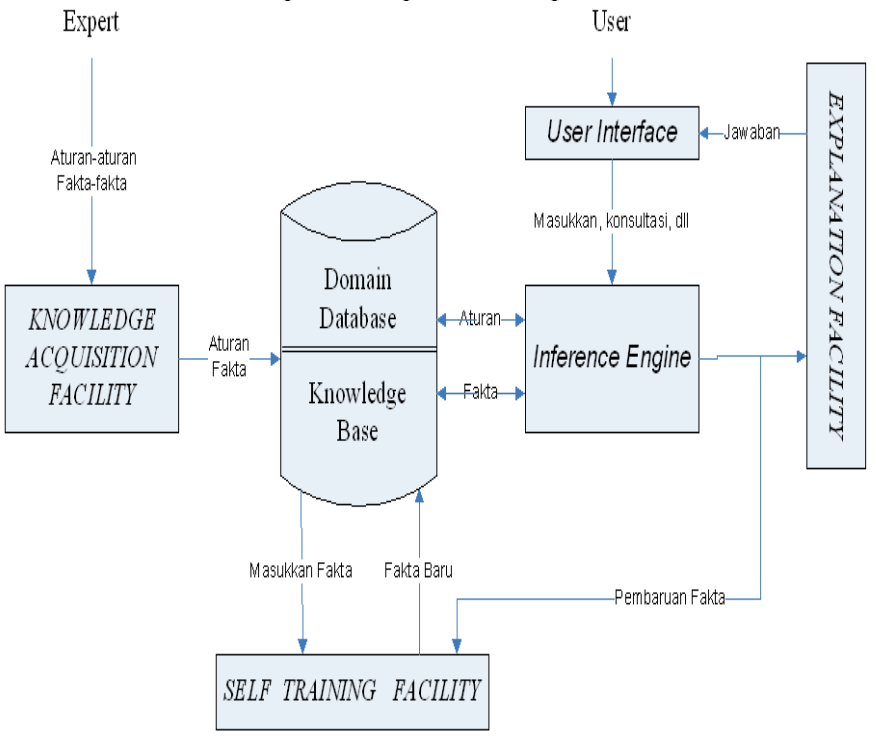

Gambar 1. Arsitektur Sistem Pakar

Ketiga arsitektur sistem pakar ini tergabung menjadi satu dalam suatu sistem sehingga terlihat kinerja dari sistem pakar ini sangat membantu dalam suatu tingkat penyelesaian terhadap masalah yang ada.

6. Keuntungan dan Kelemahan Sistem Pakar

a. Keuntungan Sistem Pakar
Beberapa keuntungan penerapan sistem pakar adalah sebagai berikut :

1) Waktu kerja menjadi lebih hemat.

2) Pekerjaan menjadi lebih sederhana.

3) Menjadikan seorang yang masih awam, bekerja layaknya seorang pakar.

4) Arsip terpercaya dari sebuah keahlian tertentu, sehingga bagi pemakai sistem pakar akan seolaholah berkonsultasi atau berkomunikasi langsung dengan sang pakar, walaupun pakar itu sudah meningal.

5) Produktititas menjadi meningkat akibat meningkatnya kualitas hasil pekerjaan / produksi, meningkatnya hal itu dikarenakan meningkatnya efisiensi kerja.

6) Memperluas jangkauan, dari keahlian seorang pakar. Dimana sistem pakar yang telah disahkan, akan sama saja artinya dengan seorang pakar yang tersedia dalam jumlah besar (dapat diperbanyak dengan kemampuan yang sama persis), dapat diperoleh dan dipakai dimana saja.

7) Dapat menggabungkan kemampuan atau pengalaman seorang pakar dengan para pakar yang lain, sehingga diperoleh sebuah hasil layaknya kita berkonsultasi dengan banyak pakar.

b. Kelemahan Sistem Pakar

Selain keuntungan-keuntungan tersebut di atas, sistem pakar seperti halnya sistem lain, juga memiliki kelemahan diantaranya adalah :

1) Masalah dalam mendapatkan pengetahuan, dimana pengetahuan tidak selalu bisa didapatkan dengan mudah, karena kadangkala pakar dari masalah yang kita buat tidak ada, dan kalaupun ada kadangkadang pendekatan yang dimiliki oleh pakar berbeda-beda.

2) Untuk membuat suatu sistem pakar yang benarbenar berkualitas tinggi sangatlah sulit dan memerlukan biaya yang sangat besar untuk pengembangan dan pemeliharaannya.

3) Bisa jadi sistem tidak dapat membuat keputusan.

4) Sistem pakar tidaklah $100 \%$ menguntungkan. Oleh karena itu diuji ulang secara teliti sebelum digunakan.

\section{METODE PENELITIAN}

\section{A. Objek Penelitian}

Adapun objek dari penelitian ini adalah sistem pakar pendiagnosa kerusakan pada televise berwarna. 


\section{B. Pendekatan Penelitian}

Adapun pendekatan penelitian yang digunakan dalam penelitian ini adalah penelitian pengembangan.

\section{Teknik Analisis Data}

Analisis data tentang pengembangan sistem pakar pendiagnosa kerusakan televisi berwarna menggunakan teknik analisis deskriptif kualitatif.

\section{HASIL DAN PEMBAHASAN}

\section{A. Hasil}

Adapun hasil dari pengembangan sistem pakar pendiagnosa kerusakan televisi berwarna yaitu berupa aplikasi desktop yang memanfaatkan database Access dan bahasa pemrograman Visual Basic 6.0. Tampilan pertama dari sistem pakar ini adalah diawali dengan tapilan form login. Dimana form login ini menyediakan user id dan password untuk para pengguna sehingga pengguna bisa mendapatkan akses ke form utama. Adapun tampilan aplikasi selengkapnya dapat dilihat pada Gambar 2 s/d Gambar 10 berikut ini.

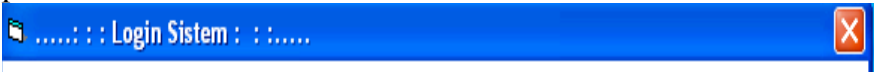

\section{Sistem Pakar Diagnosis Kerusakan Pada TV Berwarna}
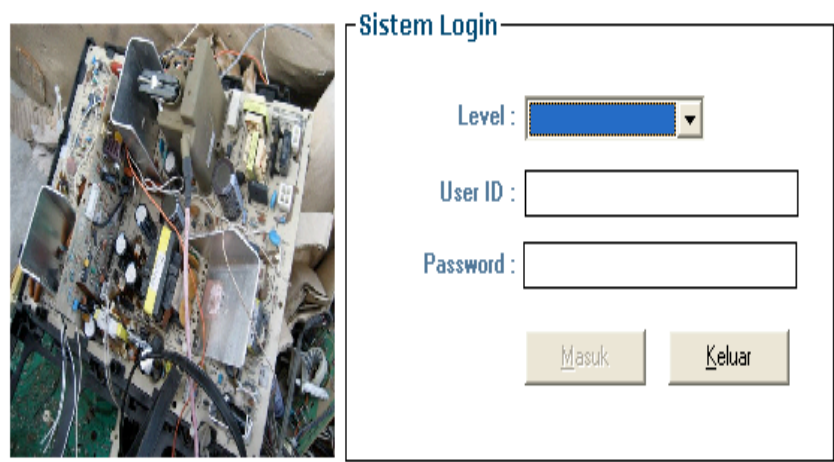

Buat Pakar Baru | Ganti Password Pakar Hapus Pakar

Gambar 2. Tampilan Form Login

Pada tampilan diatas terlihat tampilan form login untuk bisa mendapatkan akses ke form utama, seperti yang ditunjukkan pada Gambar 10 berikut ini.

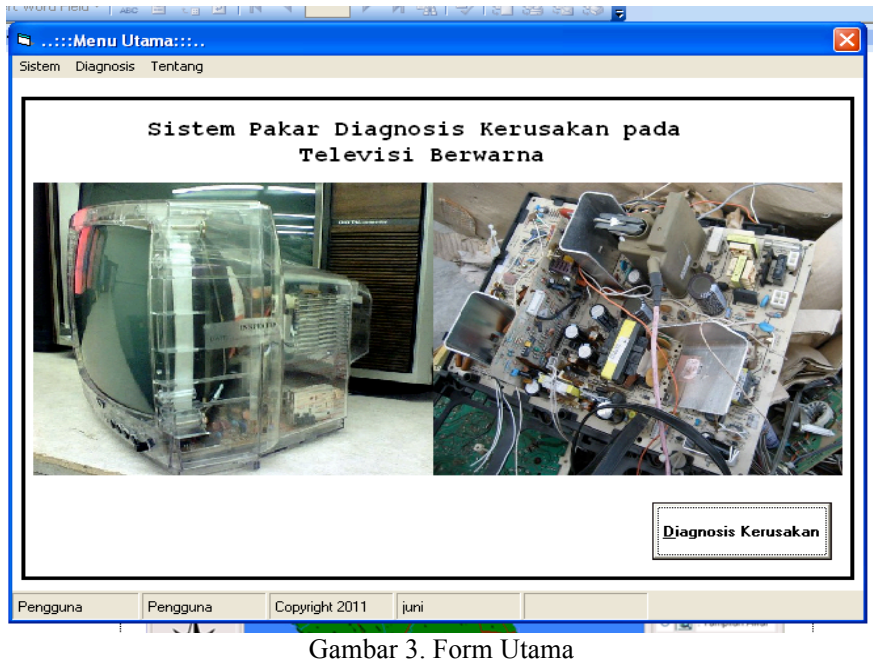

Setelah muncul form utama seperti diatas, maka selanjutnya pengguna dapat mengunakan fasilitas yang sudah disediakan pada form-form seperti yang ditunjukkan pada Gambar 11 s/d Gambar 17 berikut ini.

1. Form Pilih Kerusakan

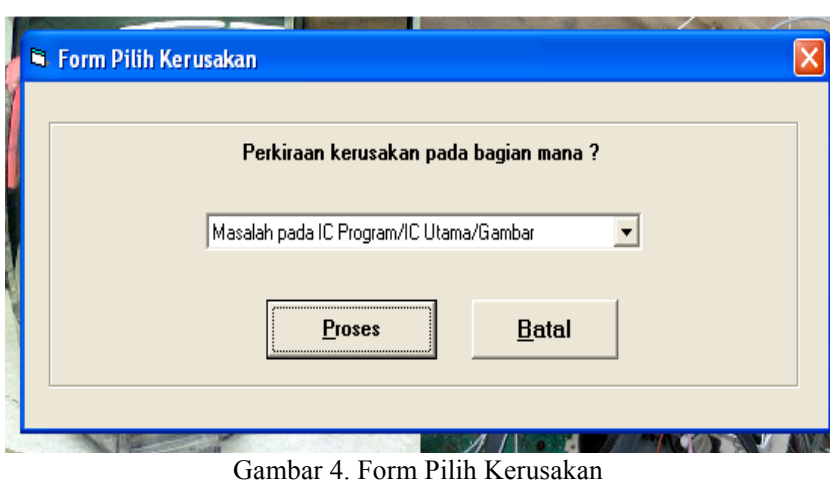

2. Form Diagnosa Kerusakan

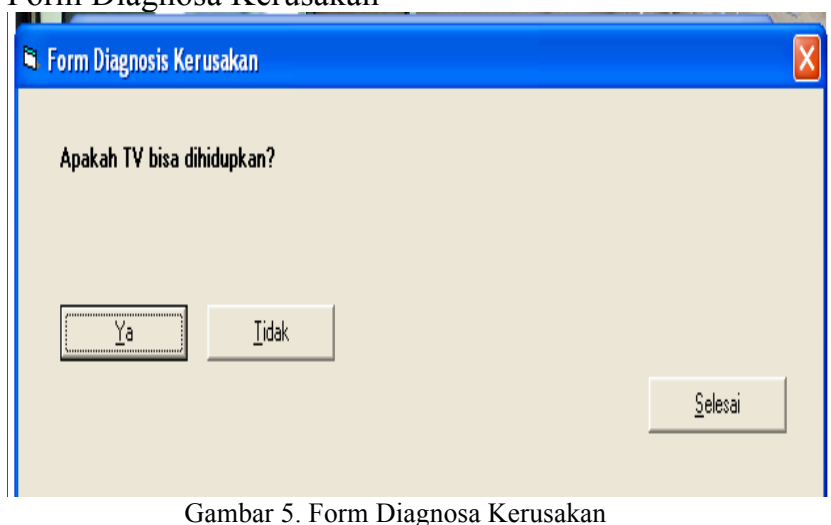

Gambar 5. Form Diagnosa Kerusakan 
3. Form Hasil Diagnosis

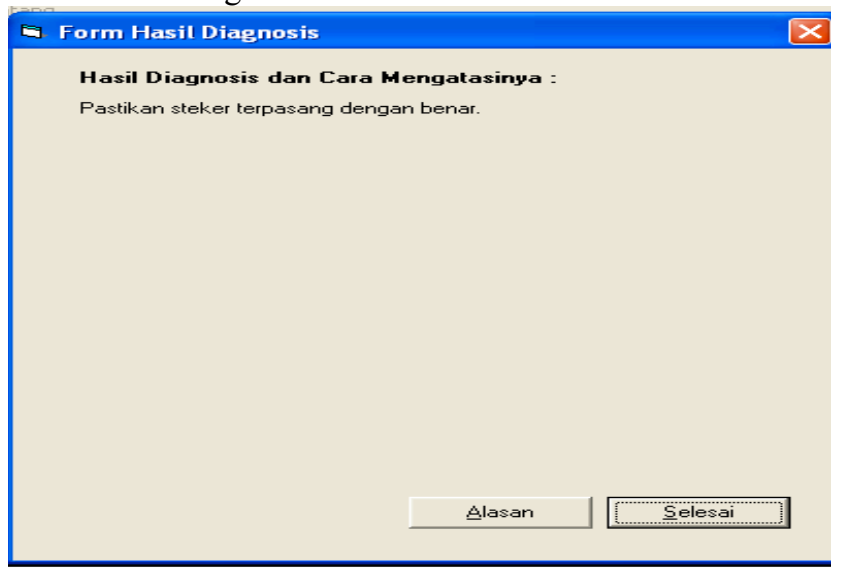

Gambar 6. Form Hasil Diagnosis

4. Form Penanganan

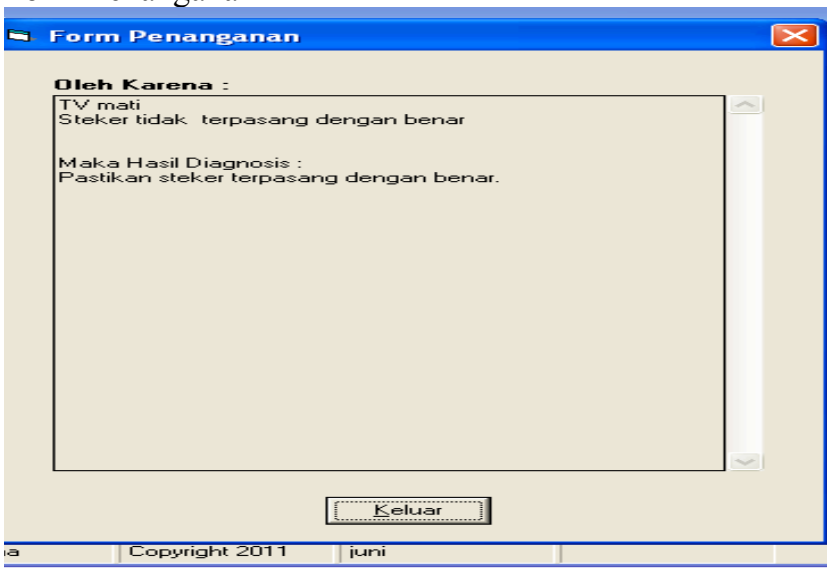

Gambar 7.Form Penanganan

5. Form Edit Pengetahuan

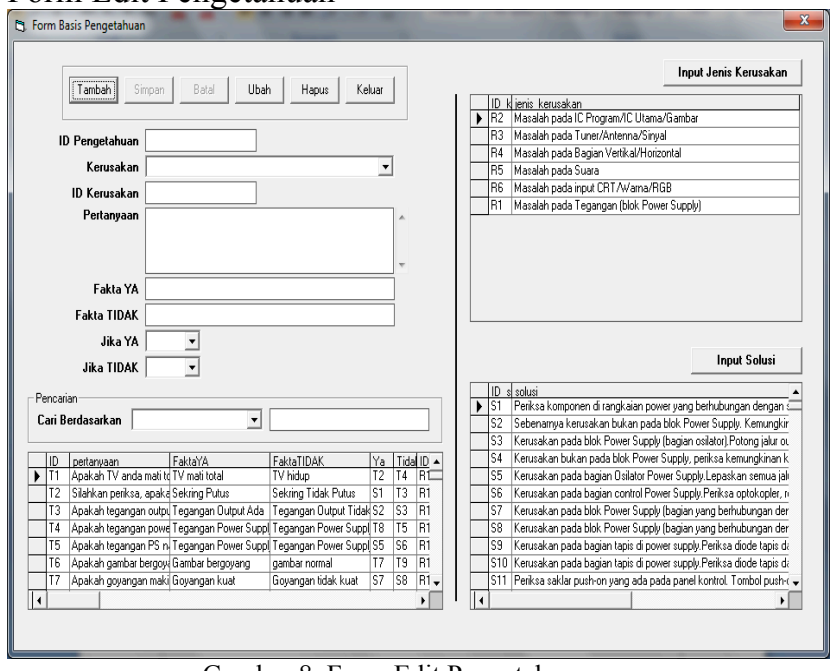

Gambar 8. Form Edit Pengetahuan

6. Form Input Solusi

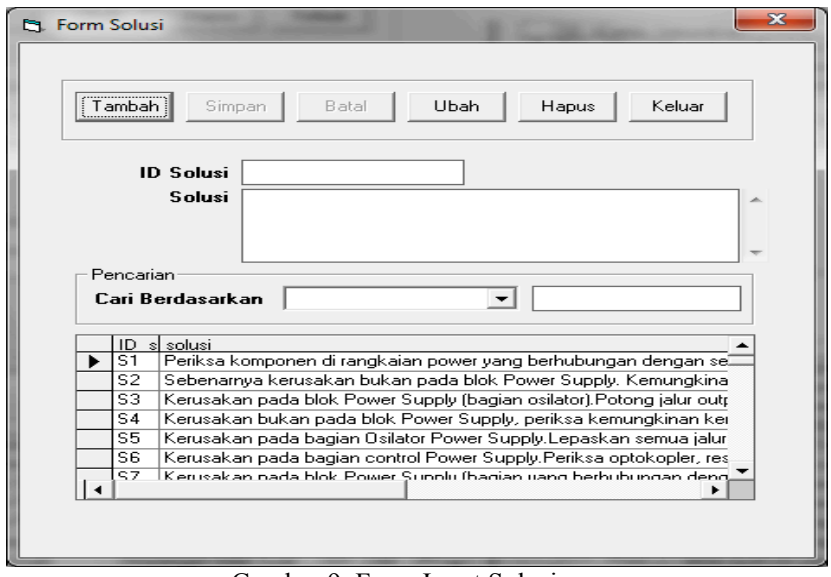

Gambar 9. Form Input Solusi

7. Form Input Jenis Kerusakan

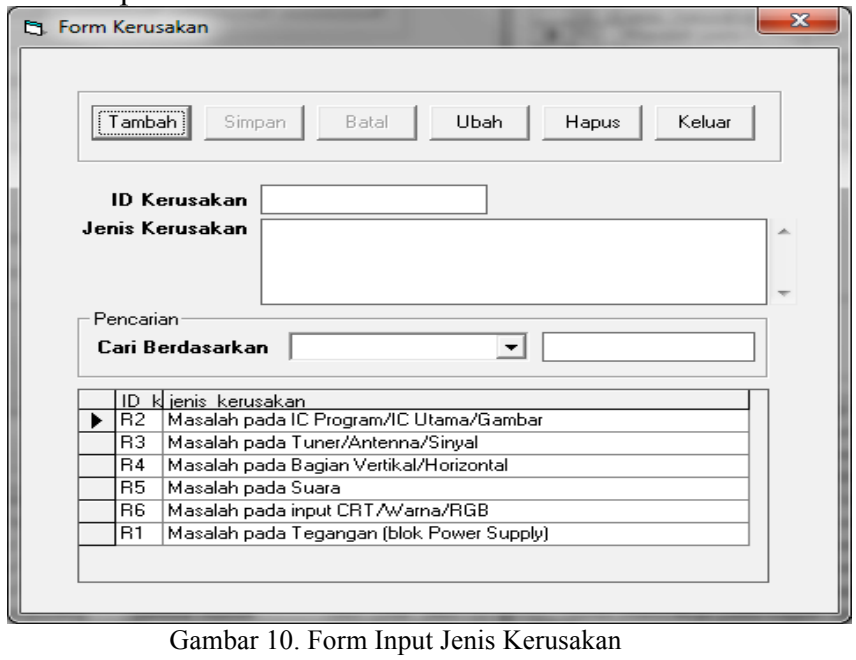

\section{B. Pembahasan}

Aplikasi sistem pakar pendiagnosa kerusakan televisi berwarna dapat terbentuk karena adanya perancangan konseptual yang matang. Adapun pembahasan tentang perancangan konseptual dari sistem pakar ini dapat dijelaskan sebagai berikut.

\section{Perancangan DFD}

\section{a. Diagram Konteks}

DFD merupakan representasi paling penting dan popular di dalam memodelkan aliran data. DFD juga menggambarkan sebuah sistem sebagai sebuah jaringan dari proses-proses fungsional, menghubungkan satu sama lainnya melalui "pipelines" dan "holding thans" of data.

Pada bagian ini penulis menerangkan Data Flow Diagram dari sistem yang telah dibuat, dimana pada bagian pertama menjelaskan Diagram Konteks yang merupakan awal gambaran proses alur data secara keseluruhan. Adapun 
gambar dari Diagram Konteks dari sistem ini ditunjukkan pada Gambar 11 berikut.

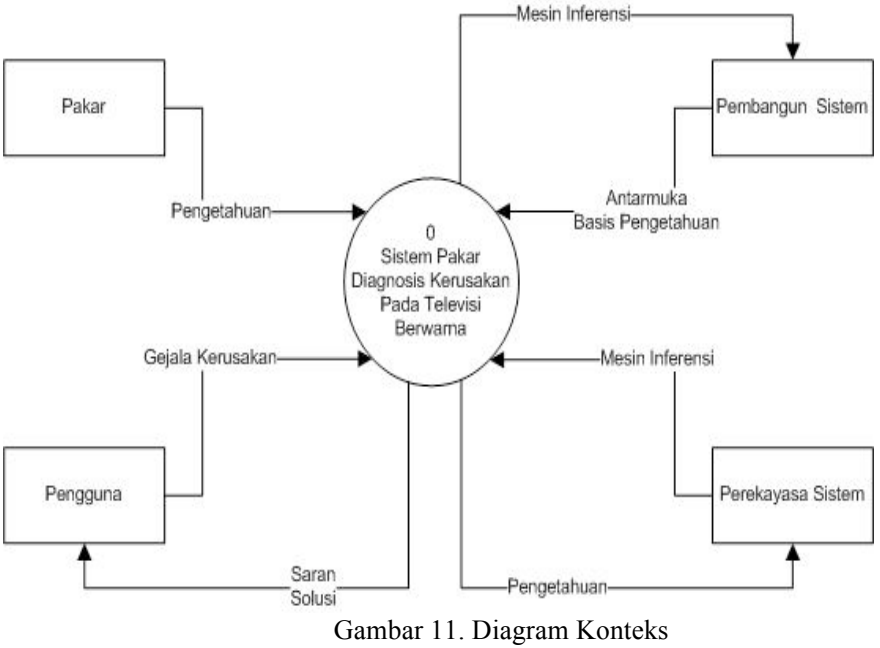

\section{b. DFD (Data Flow Diagram) Level}

Diagram Konteks diatas akan dipecah menjadi alur yang lebih detail dan akan menjadi DFD level seperti ditunjukan pada Gambar 12 berikut.

1) DFD Level 0

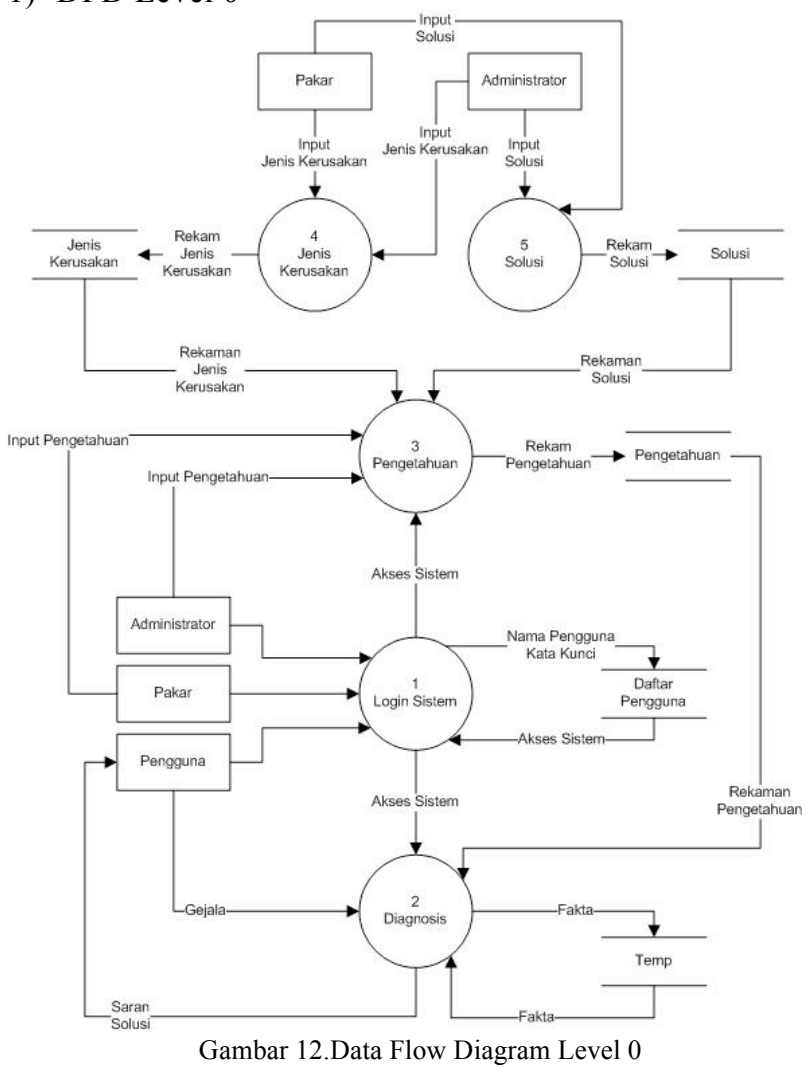

2) DFD Level 1 Proses Login

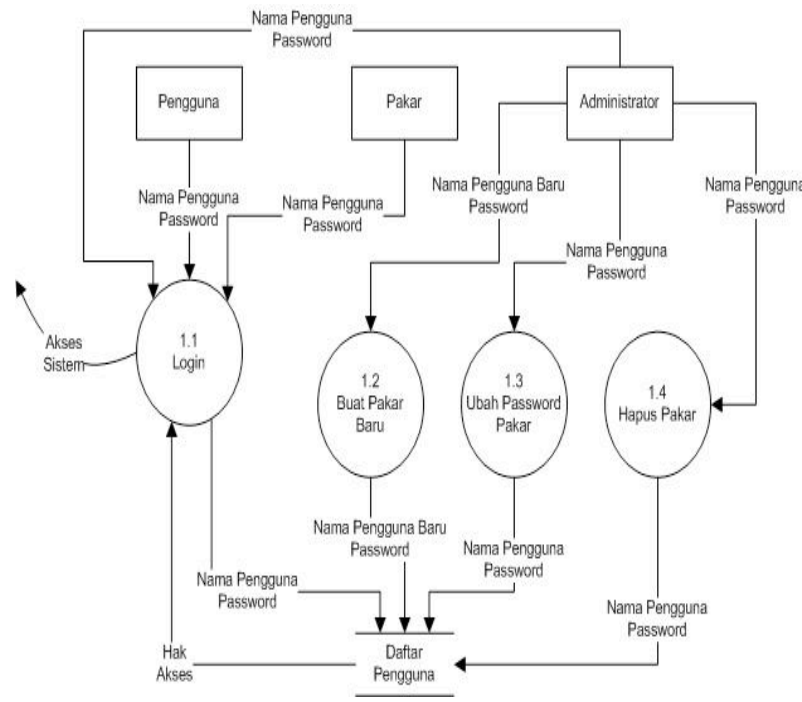

Gambar 13. Data Flow Diagram level 1 Proses login

3) DFD Level 1 Proses Diagnosis

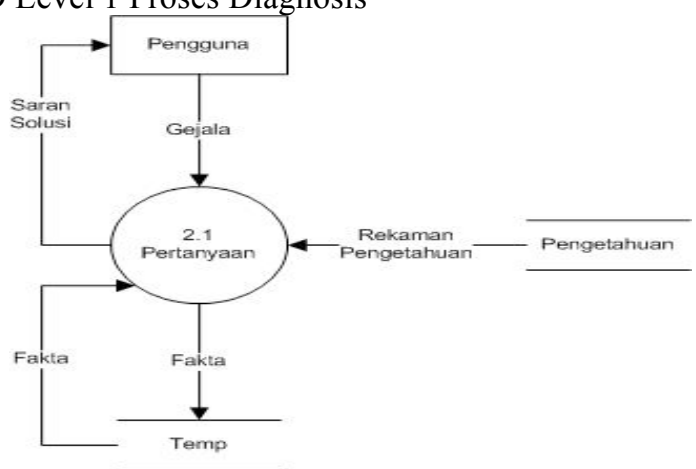

Gambar 14. Data Flow Diagram level 1 Proses Diagnosis

4) DFD Level 1 Proses Pengetahuan

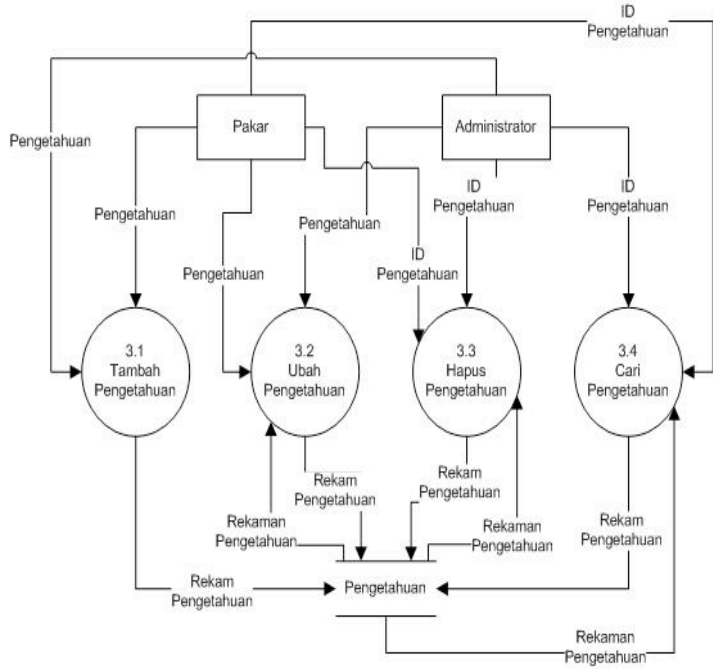

Gambar 15. Data Flow Diagram level 1 Proses Pengetahuan 5) DFD Level 1 Proses Kerusakan 


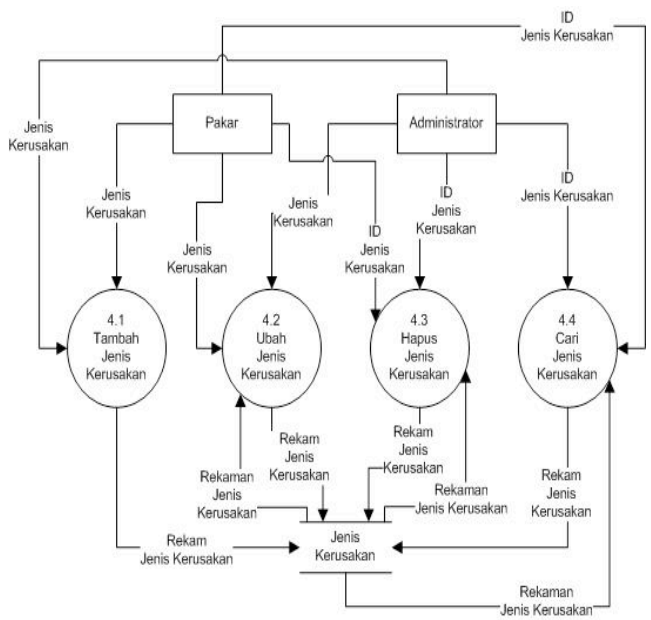

Gambar 16. Data Flow Diagram Level 1 Proses Kerusakan 6) DFD Level 1 Proses Solusi

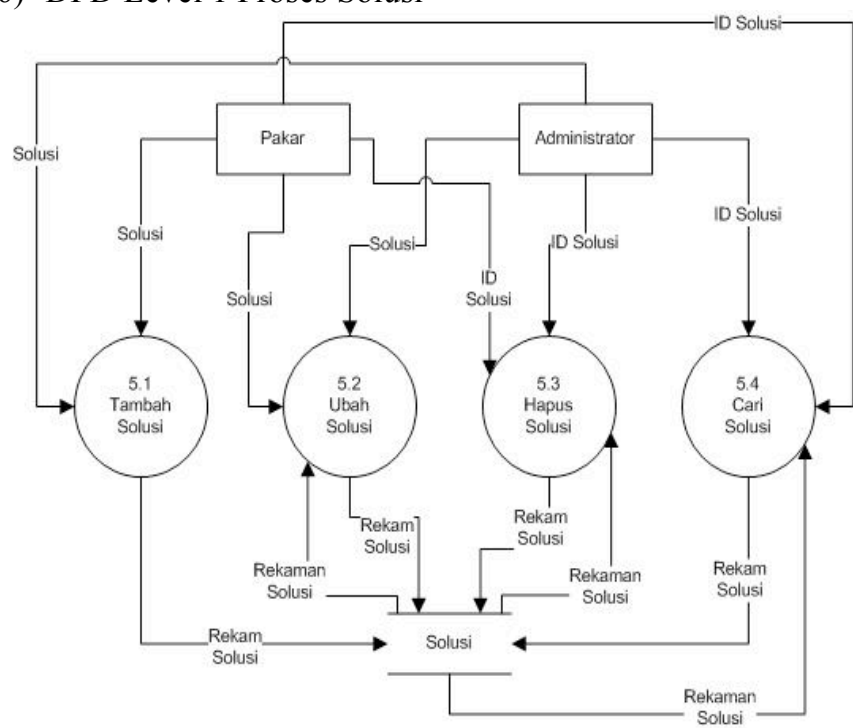

Gambar 17. Data Flow Diagram Level 1 Proses Solusi

\section{Perancangan Tabel}

Database yang dibuat pada sistem pakar ini adalah sebuah database yang diberi nama tv, database ini dibuat dengan menggunakan Microsoft Access. Berikut ini adalah namanama tabel yang ada pada database $t v$.

a. Tabel Jenis Kerusakan

Tabel 1. Jenis Kerusakan

\begin{tabular}{|c|l|l|l|l|l|}
\hline No & Key & Field & Type & Length & \multicolumn{1}{|c|}{ Ket } \\
\hline 1 & PK & ID_Kerusakan & Text & 50 & $\begin{array}{l}\text { Nomor setiap } \\
\text { kerusakan }\end{array}$ \\
\hline 2 & & Jenis_kerusakan & Text & 255 & $\begin{array}{l}\text { Jenis-jenis } \\
\text { kerusakan yang } \\
\text { ada }\end{array}$ \\
\hline
\end{tabular}

b. Tabel Pengetahuan
Tabel 2. Pengetahuan

\begin{tabular}{|c|c|c|c|c|l|}
\hline No & Key & Field & Type & Length & \multicolumn{1}{|c|}{ Ket } \\
\hline 1 & PK & ID & Text & 50 & Nomor pengetahuan \\
\hline 2 & & Pertanyaan & Text & 255 & $\begin{array}{l}\text { Pertanyaan yang } \\
\text { merujuk pada gejala- } \\
\text { gejala kerusakan }\end{array}$ \\
\hline 3 & & FaktaYA & Text & 50 & $\begin{array}{l}\text { Fakta dari pertanyaan } \\
\text { jika jawabanya YA }\end{array}$ \\
\hline 4 & & Fakta & Text & 50 & $\begin{array}{l}\text { Fakta dari pertanyaan } \\
\text { jika jawabannya } \\
\text { TIDAK }\end{array}$ \\
\hline 5 & & Ya & Text & 50 & $\begin{array}{l}\text { Aturan baru yang } \\
\text { harus dilakukan jika } \\
\text { jawabannya YA }\end{array}$ \\
\hline 6 & & Tidak & Text & 50 & $\begin{array}{l}\text { Aturan baru yang } \\
\text { harus dilakukan jika } \\
\text { jawabanya TIDAK }\end{array}$ \\
\hline 7 & FK & $\begin{array}{c}\text { ID } \\
\text { kerusakan }\end{array}$ & Text & 50 & $\begin{array}{l}\text { Nomor dari setiap } \\
\text { jenis kerusakan }\end{array}$ \\
\hline
\end{tabular}

c. Tabel List User

Tabel 3. List User

\begin{tabular}{|c|c|c|c|c|l|}
\hline No & Key & Field & Type & Length & \multicolumn{1}{|c|}{ Ket } \\
\hline 1 & PK & user_id & Text & 50 & $\begin{array}{l}\text { Nama pengguna } \\
\text { untuk masuk kedalam } \\
\text { program }\end{array}$ \\
\hline 2 & & Pass & Text & 50 & $\begin{array}{l}\text { Password pengguna } \\
\text { untuk masuk kedalam } \\
\text { program }\end{array}$ \\
\hline 3 & & Level & Text & 50 & $\begin{array}{l}\text { Level yang } \\
\text { menentukan hak } \\
\text { akses dari setiap } \\
\text { pengguna }\end{array}$ \\
\hline
\end{tabular}

d. Tabel Solusi

Tabel 4. Solusi

\begin{tabular}{|c|c|c|c|c|l|}
\hline No & Key & Field & Type & Length & \multicolumn{1}{|c|}{ Ket } \\
\hline 1 & PK & ID_solusi & Text & 50 & $\begin{array}{l}\text { Nomor dari setiap } \\
\text { solusi }\end{array}$ \\
\hline 2 & & Solusi & Memo & & $\begin{array}{l}\text { Jenis jenis solusi } \\
\text { yang ada }\end{array}$ \\
\hline
\end{tabular}

e. Tabel Temp

Tabel 5. Temp

\begin{tabular}{|c|c|c|c|c|l|}
\hline No & Key & Field & Type & Length & \multicolumn{1}{|c|}{ Ket } \\
\hline 1 & PK & ID_temp & Text & 50 & $\begin{array}{l}\text { Nomor tempat } \\
\text { penyimpanan jawaban } \\
\text { dari setiap pertanyaan } \\
\text { bersifat sementara }\end{array}$ \\
\hline 2 & & Fakta & Text & 50 & $\begin{array}{l}\text { Tempat penyimpanan } \\
\text { fakta dari setiap } \\
\text { pertanyaan yang dijawab } \\
\text { bersifat sementara }\end{array}$ \\
\hline
\end{tabular}

3. Pemanfaatan Metode Forward Chaining 
Metode yang digunakan adalah Metode Forward Chaining (Pelacakan ke Depan), menggunakan pendekatan Data (Data Driven). Aturan forward chaining dapat digunakan untuk menciptakan beberapa aturan baru. Beberapa gambar berikut merupakan Tree dari setiap jenis kerusakan.

a. Kerusakan Pada Tegangan (Blok Power Supply)

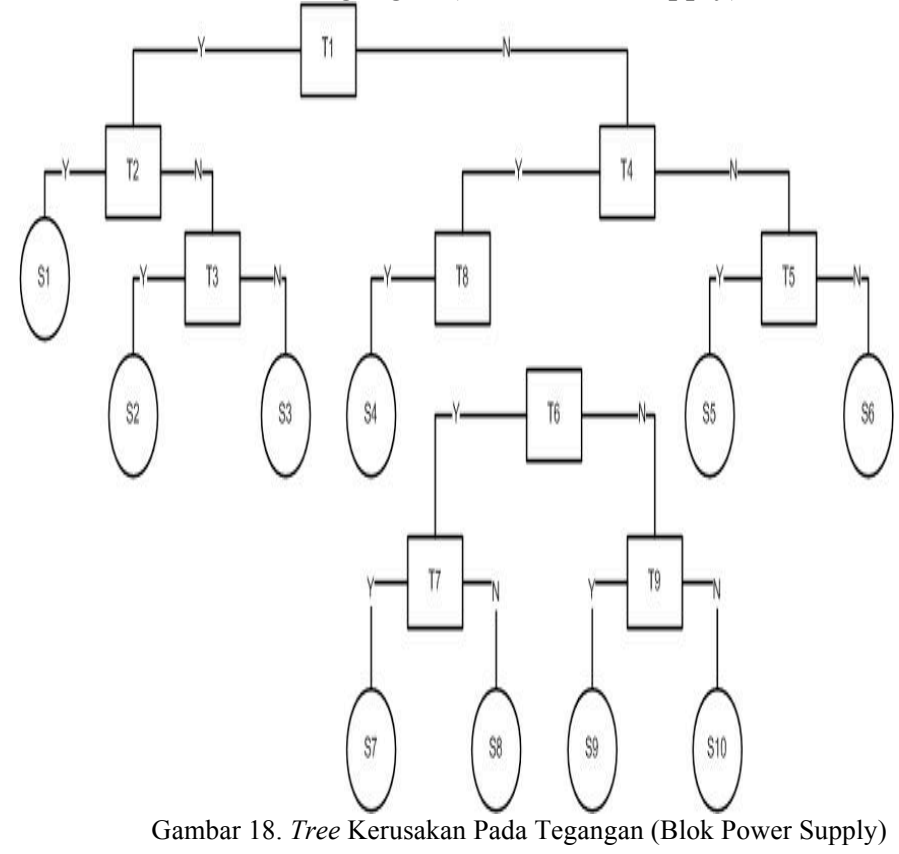

b. Kerusakan Pada IC Program/IC Utama/Gambar

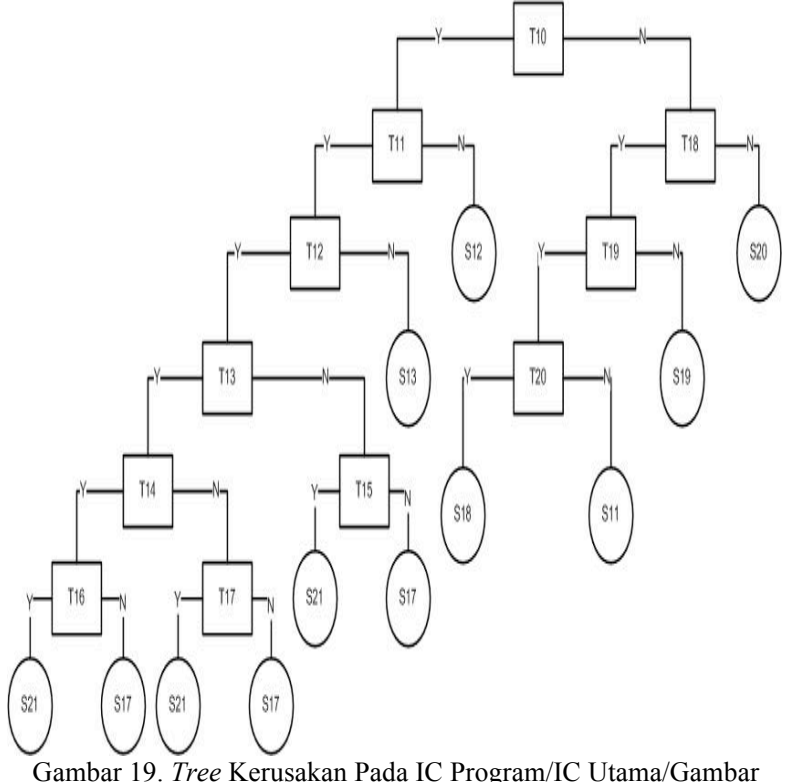

c. Kerusakan Pada Tuner/Antenna/Sinyal

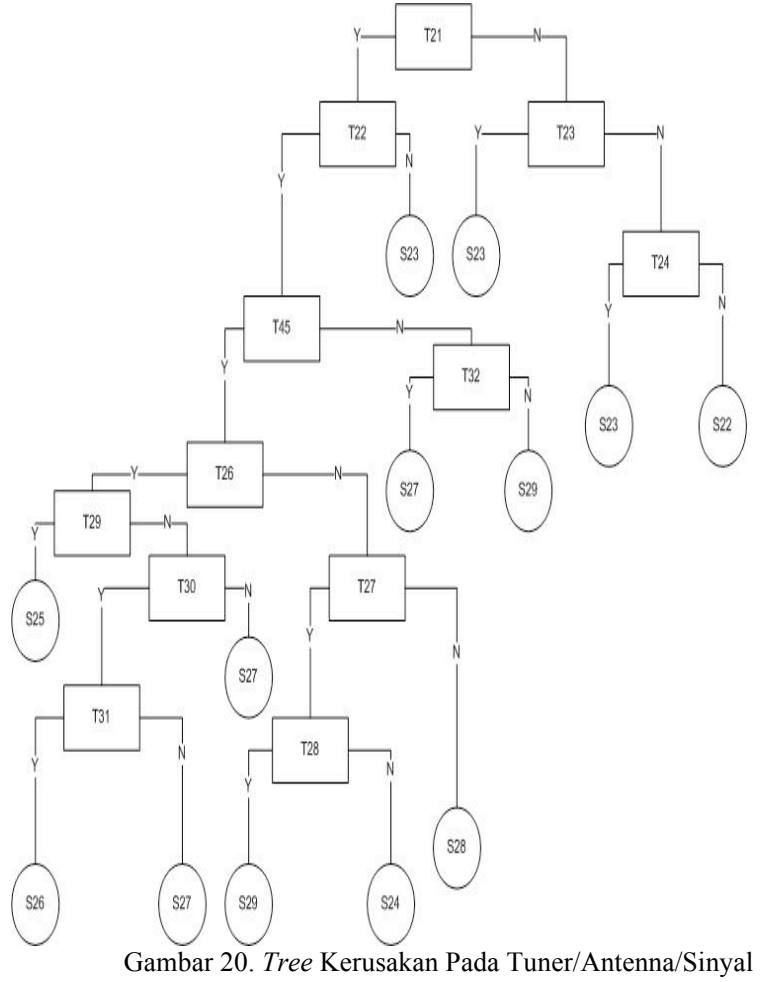

d. Kerusakan Pada Bagian Vertikal/Horizontal

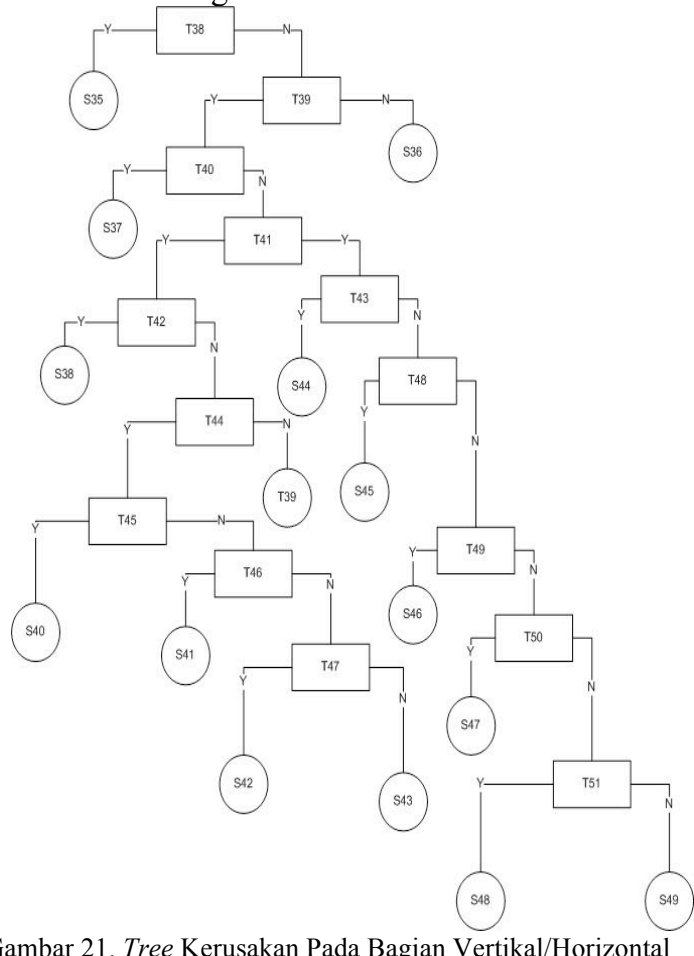

e. Kerusakan Pada Suara 


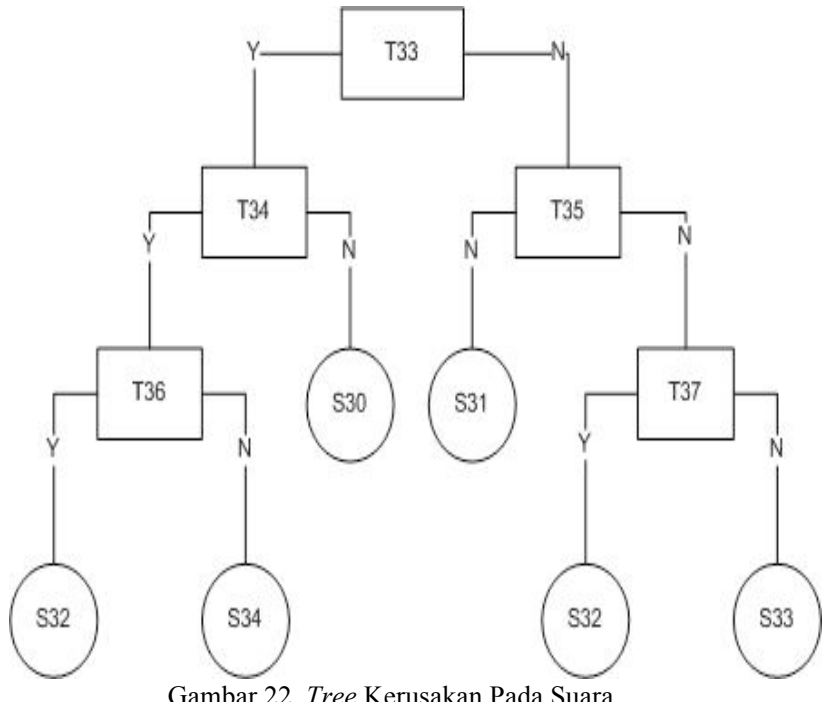

Gambar 22. Tree Kerusakan Pada Suara

f. Kerusakan Pada Input CRT/Warna/RGB

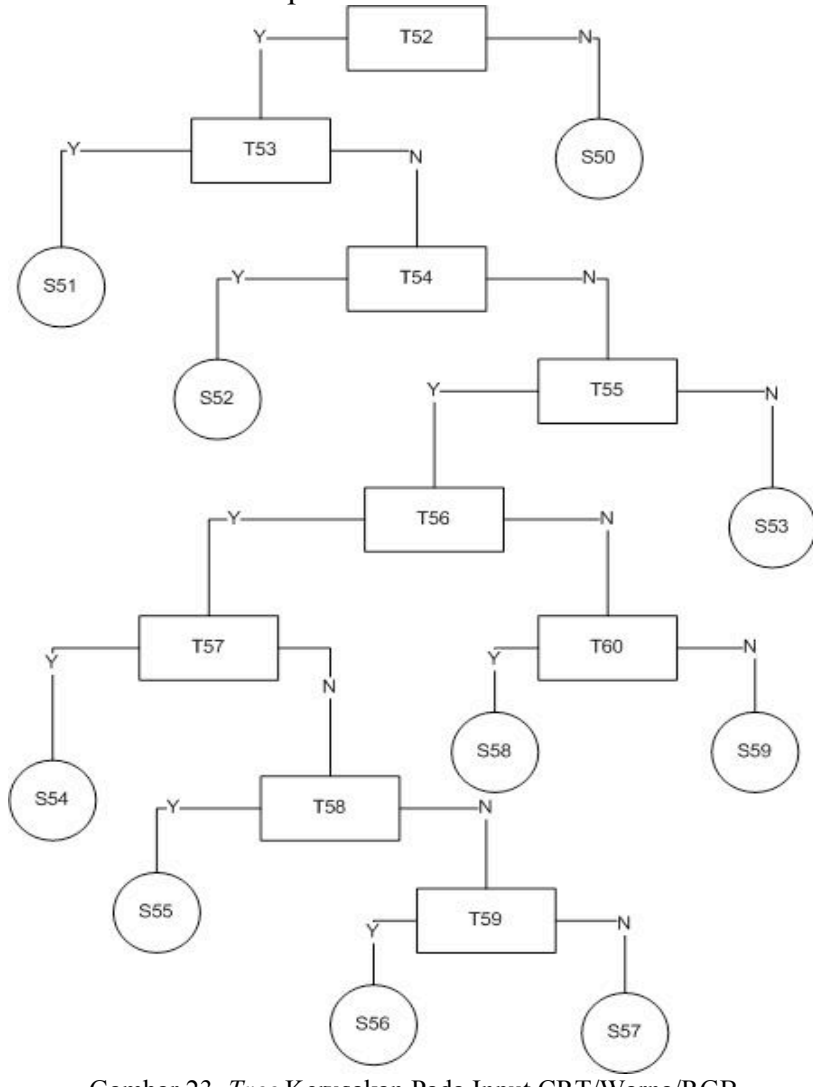

Gambar 23. Tree Kerusakan Pada Input CRT/Warna/RGB

\section{KESIMPULAN}

Berdasarkan hasil dan pembahasan sebelumnya, maka dapat ditarik beberapa kesimpulan antara lain:

1. Pengembangan sistem pakar untuk diagnosis kerusakan pada televisi berwarna dilakukan dengan pembentukan pohon keputusan (tree) sehingga memiliki kedinamisan dalam manajemen pengetahuan/kepakaran.

2. Pemilihan bahasa visual basic 6.0 dan database Access akan memberikan fleksibelitas dalam pengembangan aplikasi.

3. Pendekatan pengembangan user interface dilengkapi dengan fasilitas pengenalan istilah dan dokumen penunjang dapat memberikan kemudahan pemakaian bagi pemakai awam.

\section{DAFTAR PUSTAKA}

[1] D.B. Sanjaya, dan D.G.H. Divayana, "An Expert System-Based Evaluation of Civics Education as a Means of Character Education Based on Local Culture in the Universities in Buleleng," in International Journal of Advanced Research in Artificial Intelligence, Vol. 4, No.12, 2015, pp. $17-21$

[2] J.C. Giarratano, and G. Riley, Expert Systems : Principles and Programming $4^{\text {th }}$ Edition. USA : PWS Publishing Co, 2004.

[3] A. A. Hopgood, Intelligent Systems for Engineers and Scientists $\left(^{\text {nd }}\right.$ Edition). USA : CRC Press, 2001

[4] Y. Qu, F. Tao, and H. Qui, "A Fuzzy Expert System Framework Using Object Oriented Techniques," in IEEE Pacific-Asia Workshop on Computational Intelligence and Industrial Application, 2008, pp. 474 477.

[5] D.G.H. Divayana, "Development of Duck Diseases Expert System with Applying Alliance Method at Bali Provincial Livestock Office," in International Journal of Advanced Computer Science and Applications, Vol. 5, No. 8, 2014, pp.48-54.

[6] S. Kusumadewi, Artificial Intelligence (Teknik dan Aplikasinya). Yogyakarta : Graha Ilmu, 2003.

[7] I.P.W. Ariawan, D.B. Sanjaya, dan D.G.H. Divayana, "An Evaluation of the Implementation of Practice Teaching Program for Prospective Teachers at Ganesha University of Education Based on CIPP-Forward Chaining," in International Journal of Advanced Research in Artificial Intelligence, Vol. 5, No.2, 2016, pp. 1-5. 